Supporting Information

\title{
Switchable Microvalves Employing a Conducting Polymer and Their Automatic Operation in Conjunction with Micropumps with a Superabsorbent Polymer
}

\author{
Shishir Kanti Pramanik and Hiroaki Suzuki* \\ Graduate School of Pure and Applied Sciences, University of Tsukuba,
}

Tsukuba, Ibaraki 305-8573

* Corresponding authors.

E-mail addresses: hsuzuki@ims.tsukuba.ac.jp 
Preparation of Electrodes and Microfluidic Structures. To form the platinum electrodes, a glass substrate was cleaned in a boiled solution containing water, $25 \% \mathrm{NH}_{3}$, and $30 \% \mathrm{H}_{2} \mathrm{O}_{2}$ in a 4:1:1 volumetric ratio. The substrate was then rinsed with boiled ultra-pure water twice. The cleaned substrate was dried by blowing dry nitrogen gas. Platinum (300-nm thick) was deposited on a glass substrate by sputtering with a 50-nm-thick chromium intermediate layer. The electrode patterns were formed by the lift-off process.

PDMS microfluidic structures were prepared by replica molding using a mold formed with a thick-film photoresist SU-8 25. Through-holes with a diameter of $4 \mathrm{~mm}$ were made for injecting the solutions and introducing SP discs on the PDMS substrate by punching (punch no. 1256, Takashiba Gimune Seisakujo, Hyogo, Japan).

Characterization of the Doped PPy Film. NaDS or NaDBS was used as the surfactant, and the time required for polymerization was optimized by measuring the changes in the wettability of the doped PPy film. An as-deposited film and electrochemically reduced and oxidized films were compared. The wettability was evaluated by measuring the contact angle of a water droplet $(1 \mu \mathrm{L})$ placed on the film using a contact angle meter (Model G-1-1000, ERMA, Tokyo, Japan). The electrochemical cell used to change the redox state was the same as the one used for the synthesis of the PPy films. After immersing the NaDBS or NaDS-doped PPy film in a $100 \mathrm{mM} \mathrm{KCl}$ solution, we applied a voltage of $-0.8 \mathrm{~V}$ to the platinum electrode for $90 \mathrm{~s}$ to reduce the oxidized PPy. The film was rinsed with ultra-pure water and dried by blowing dry nitrogen gas. The contact angle was then measured. Further, the film was immersed in a $100 \mathrm{mM} \mathrm{KCl}$ solution, and PPy was oxidized again at $+0.6 \mathrm{~V}$ for $90 \mathrm{~s}$. After rinsing the film in ultrapure water and drying it by blowing dry nitrogen gas, we measured the contact angle in the same manner. Six measurements were made, and the averages were taken.

Characterization of the Valve. A simple microfluidic device was constructed by bonding a glass substrate with the valve and a PDMS substrate with a flow channel (Figure S1A). The two substrates were adhered by manually applying a small pressure to the PDMS surface. The height of the flow channel was $80 \mu \mathrm{m}$ for all the devices, and the channel width was varied from 500 to $1000 \mu \mathrm{m}$.

To characterize the valve, a dye solution containing $100 \mathrm{mM}$ of $\mathrm{KCl}$ was first injected into the flow channel. A commercial Ag/AgCl electrode (2080 A-06T, Horiba, Kyoto, Japan) was then inserted into the solution inlet, and a potential was applied to the valve electrode using a potentiostat (HA-151, Hokuto Denko, Tokyo, Japan) with respect to the $\mathrm{Ag} / \mathrm{AgCl}$ electrode (Figure S1A). Unless otherwise specified, the applied potential was $-0.9 \mathrm{~V}$ for all the experiments shown in Figures 3, 4, and 6. The movement of 
the solution was observed under a microscope (Multi-Viewer System VB-S20, Keyence, Osaka, Japan). All the experiments were carried out at $25^{\circ} \mathrm{C}$.

Preparation of Freeze-Dried Polymer Discs. Superabsorbent cylindrical discs made of SAP were prepared as follows (Figure S2). ${ }^{1}$ First, a thick SP gel was prepared by dissolving $100 \mathrm{mg}$ of SP in $600 \mu \mathrm{L}$ of water in a centrifuge tube. The solution was stirred vigorously using a stick. Subsequently, 100 mg of CA was added and mixed well, and $200 \mu \mathrm{L}$ of water and $50 \mathrm{mg}$ of CA were again added to the mixture, and the mixture was stirred. Thereafter, a semi-solid gel containing inert supporting material (CA) was obtained. To prepare cylindrical compact discs, fragments of the gel was put into a PDMS template with circular through-holes (diameter: $3.5 \mu \mathrm{m}$ ) formed by punching and placed on a glass wafer. The semi-solid gel in the template was maintained at a temperature of $-80^{\circ} \mathrm{C}$ for $2 \mathrm{~h}$, followed by freezedrying at $-50{ }^{\circ} \mathrm{C}$ for $3.5 \mathrm{~h}$. Thus, we obtained polymer discs with a porous structure and an SP-to-CA ratio of 1:1.5. The polymer discs were stored in an air tight container to avoid contact with humid air.

Formation of Through-Holes on Glass Substrates. Circular through-holes (diameter: 0.75 $\mathrm{mm}$ ) were formed on a glass substrate by sand-blasting through patterns of a dry film photoresist. To prepare the dry film photoresist patterns, the substrate was placed on a hot plate and heated for $120 \mathrm{~s}$ at $100{ }^{\circ} \mathrm{C}$. Subsequently, the dry film photoresist was carefully placed on the hot substrate. UV light was then illuminated onto the photoresist through a photomask using a mask aligner. After development in a $0.2 \% \mathrm{Na}_{2} \mathrm{CO}_{3}$ solution for $3-5 \mathrm{~min}$ at $30{ }^{\circ} \mathrm{C}$, the patterns for the through-holes were obtained. The through-holes were formed by sand-blasting through the photoresist patterns at a constant pressure of 75 $\mathrm{kPa}$ using a sand-blaster (Pneuma-Blaster, Fuji Manufacturing, Tokyo, Japan). After sand-blasting, the substrate was immersed in a solution containing $3 \mathrm{wt} \% \mathrm{NaOH}\left(40{ }^{\circ} \mathrm{C}\right)$, and the dry film photoresist was removed. Finally, the substrate was cleaned in a mixture of pure water, $25 \% \mathrm{NH}_{3}$, and $30 \% \mathrm{H}_{2} \mathrm{O}_{2}$ in a volumetric ratio of 4:1:1 for $1 \mathrm{~h}$ at room temperature, rinsed with pure water, and dried with $\mathrm{N}_{2}$.

Calculation of Flow Rate. The injection flow rate, $Q$, is defined as $Q=V / t$, where $V$ is the volume of the chamber, and $t$ is the time required for the reaction chamber to be completely filled with a solution. The extraction flow rate was calculated in a similar manner.

Optimizing the Structure of the Injection Micropump. To optimize the size of the pumping chamber of the injection micropump, independent injection micropumps with cylindrical pumping chambers of different diameters were fabricated. The height of the chamber was $2 \mathrm{~mm}$. The dimensions of the actuation chamber (diameter $4 \mathrm{~mm}$, height $3 \mathrm{~mm}$ ) were the same for all cases. 
Table S1: Dimensions of the components used in the microfluidic unit.

\begin{tabular}{|c|c|c|}
\hline PDMS layer & Component & Dimensions \\
\hline \#1 (bottom) & $\begin{array}{l}\text { Reaction chamber } \\
\text { Inlet solution reservoirs } \\
\text { Pumping chamber for the injection pump } \\
\text { Chamber for the suction pump } \\
\text { Air vents } \\
\text { Flow channels between the solution reservoir and } \\
\text { the reaction chamber }\end{array}$ & $\begin{array}{l}\text { Diameter: } 2 \mathrm{~mm} \\
\text { Diameter: } 2 \mathrm{~mm} \\
\text { Diameter: } 4.5 \mathrm{~mm} \\
\text { Height: } 2 \mathrm{~mm} \\
\text { Surface area: } 60 \mathrm{~mm}^{2} \\
\text { Diameter: } 4 \mathrm{~mm} \\
\text { Width: } 30 \mu \mathrm{m} \\
\text { Length: } 4.25 \mathrm{~mm} \\
\text { Width: } 200 \mu \mathrm{m}\end{array}$ \\
\hline \#2 (Diaphragm) & Diaphragm & Thickness: $50 \mu \mathrm{m}$ \\
\hline \#3 & $\begin{array}{l}\text { Through-hole to accommodate the cylindrical } \\
\text { polymer disc }\end{array}$ & Diameter: $4.5 \mathrm{~mm}$ \\
\hline \#4 (top) & $\begin{array}{l}\text { Priming solution reservoirs } \\
\text { Flow channel }\end{array}$ & $\begin{array}{l}\text { Diameter: } 4.5 \mathrm{~mm} \\
\text { Length: } 1 \mathrm{~mm} \\
\text { Width: } 200 \mu \mathrm{m}\end{array}$ \\
\hline
\end{tabular}

A



B



Figure S1. Structure and function of a switchable hydrophobic valve with doped PPy film. (A) Device used for the characterization of the valve. Chip size: $20 \mathrm{~mm} \times 12 \mathrm{~mm}$. A solution introduced from the inlet moves in the flow channel under capillary action but stops at the valve (left). Under the application of a potential to the valve electrode with respect to an $\mathrm{Ag} / \mathrm{AgCl}$ reference electrode (R.E.) inserted at the inlet, the solution passes through the valve area (right). (B) Platinum electrode pattern in the flow channel. 


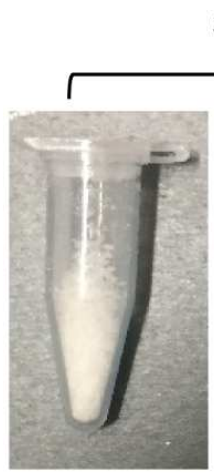

$100 \mathrm{mg} \mathrm{SP}$
Step 1



SP polymer ge



$150 \mathrm{mg} \mathrm{CA}$
Step 2



$\mathrm{SP}$ gel + CA
Step 6



Polymer disc
Step 5



Freeze dryer
SP polymer gel

Step 4
Step 3

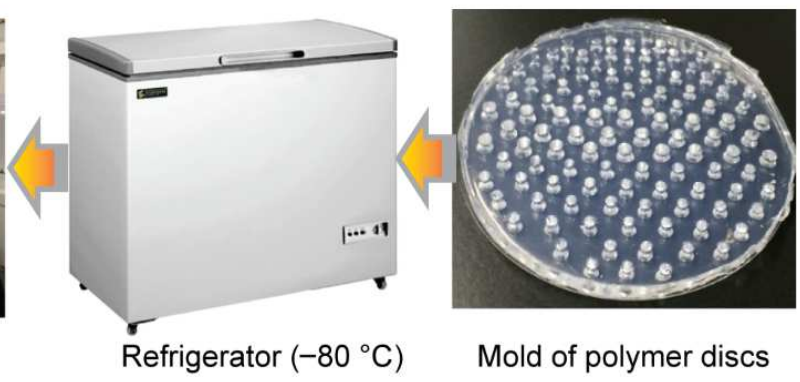

Figure S2. Schematics of the preparation of cylindrical polymer discs: (Steps 1 and 2) Preparation of the polymer gel; (Step 3) Gel placed in the PDMS mold; (Steps 4 and 5) Freeze drying of polymer gel; (Steps 6) Collection of the discs before preserving in an air tight container. 
A



C



B



D



Figure S3. Characterization of the PPy film. (A) Changes in the water contact angle on the DBS-doped PPy film grown with different polymerization times. Contact angles on the as-deposited film, reduced film $(-0.8 \mathrm{~V}$ applied), and oxidized film (+0.6 V applied) are compared. Averages and standard deviations for five repetitive measurements are shown. (B) Changes in the water contact angle on the DBS-doped PPy film. Data for the as-deposited films, reduced films, and oxidized films are shown. Averages and standard deviations for 10 repetitive measurements are shown. (C) Dependence of water contact angle on the NaDBS-doped PPy film on dopant concentration. Data for as-deposited films (green columns) and reduced films (applied potential -0.9 V) are shown. Five measurements are carried out for each data point, and the averages and standard deviations are shown. (D) Dependence of switching time on $\mathrm{pH}$ for a $100-\mu \mathrm{m}$ long valve. Averages and standard deviations for 10 repetitive measurements are shown.

Movie S1. Flow control using a 100- $\mu \mathrm{m}$ long valve formed in a straight-flow channel (500 $\mu \mathrm{m}$ wide).

Movie S2: Controlled transport of solutions by operating eight valves.

Movie S3. Exchange of multiple solutions in the integrated device. 


\section{Reference}

(1) Biswas, G. C.; Rana, M. M.; Kazuhiro, T.; Suzuki, H., A Simple Micropump Based on a FreezeDried Superabsorbent Polymer for Multiplex Solution Processing in Disposable Devices. R. Soc. Open Sci. 2019, 6, 182213. 